Statistics Canada Data Collection on Inuit: The Importance of Consultation and Context

\author{
Marika Morris \\ Adjunct Research Professor, School of Canadian Studies, Carleton University
}

aboriginal policy studies Vol. 5, no. 2, 2016, pp. 136-148

This article can be found at:

http://ejournals.library.ualberta.ca/index.php/aps/article/view/25452

ISSN: $1923-3299$

Article DOI: http://dx.doi.org/10.5663/aps.v5i2.25452

aboriginal policy studies is an online, peer-reviewed and multidisciplinary journal that publishes original, scholarly, and policy-relevant research on issues relevant to Métis, non-status Indians and urban Aboriginal people in Canada. For more information, please contact us at apsjournal@ualberta.ca or visit our website at www.nativestudies.ualberta.ca/research/aboriginal-policy-studies-aps.

UNIVERSITY OF ALBERTA

FACULTY OF NATIVE STUDIES 


\title{
Statistics Canada Data Collection on Inuit: The Importance of Consultation and Context
}

\author{
Marika Morris \\ Adjunct Research Professor, School of Canadian Studies, Carleton University
}

Abstract: The Truth and Reconciliation Commission underlined the importance of knowing the history and context of Indigenous peoples in Canada, and how today's institutions continue to be shaped by this legacy with detrimental effects. This article applies that lens to Statistics Canada data collection and reporting on Indigenous groups, particularly Inuit. Statistics Canada has already made strides in terms of consultations with national Indigenous organizations, but improvements can be made in more accurately capturing and describing Indigenous populations. These include: reviewing the definition of Métis, developing methods to include reserves and institutions ("collective dwellings") fully, outreach strategies and methodologies to include transient and homeless persons, and providing both past and present contextual information to understand better the data and to avoid inadvertently contributing to stereotypes.

\section{Introduction}

The Truth and Reconciliation Commission (2015) advised all Canadians, their governments, and their institutions to consider the legacy of residential schools. In the spirit of the TRC, this article briefly outlines how the history and context of Inuit can apply to what statistical data are collected, how they are collected, and how they are interpreted and presented to the public. The primary sources of Statistics Canada data on Inuit are from the Census, National Household Survey, and Aboriginal Peoples Survey, supplemented by data from other surveys and sources. This article deals with data sources, limitations, and access as they pertain to Inuit, and outlines some areas for improvement for data collection and gathering.

In the interests of full disclosure, the author is a member of Statistics Canada's Advisory Committee on Social Conditions, and worked closely with Statistics Canada while a Senior Policy Research Advisor at Public Safety Canada. The author has also done work as a consultant for Inuit organizations, and is influenced by this perspective, in addition to her academic training at the doctoral level in Aboriginal and Northern Issues. The impetus for this article came from two personal experiences. First, the author, in leading a participatory action research workshop in Iqaluit for Inuit women from communities in Nunavut, Nunavik and the Inuvialuit region of the Northwest Territories, heard a number of firsthand experiences participants had with researchers who had not treated them with respect either in collecting the data or in reporting the data. The second experience involved accompanying an Inuk colleague to a presentation by Statistics Canada at a conference, and having the colleague emerge in distress. The motivation for this article is to bridge a

aboriginal policy studies, vol. 5, no. 2, 2016 
number of sources of knowledge-statistical, governmental, academic, organizational and personal-in an effort to point the way to improving the collection and analysis of data on Inuit.

\section{Data Sources and Limitations}

The Census is a mandatory survey conducted among all Canadians every five years. In 2011, the Census asked only a few questions, and for about a third of Canadians (4.5 million Canadian households), was accompanied by the National Household Survey (NHS), which was conducted for the first and perhaps last time that year. The NHS replaced the long-form Census. The questions were similar to the long-form Census, but the long-form Census was mandatory and the NHS was not, so there may be differences in who responded. The NHS did not cover people in "collective dwellings," which includes penitentiaries, in which Indigenous people are overrepresented, so any Indigenous people in such dwellings do not exist in the data. However, in remote areas and on reserve, all households were invited to participate in the NHS. The non-response rate for Nunavut was twenty-five percent, compared with twenty-six percent for all of Canada (Statistics Canada 2011a). The NHS collected basic demographics, information about families and households, activity limitations, ethnic diversity and immigration, language, Aboriginal identity, mobility and migration, education, labour, transportation to work, income and earnings, and housing and shelter costs. Since it is aimed at a sample of all Canadians, it is the best source of information that compares Indigenous to non-Indigenous Canadians.

Comparing the Inuit data to First Nations and Métis data is problematic, because the data collection for each of these groups is flawed. There were thirty-six reserves that were enumerated incompletely or not at all for the 2011 NHS. In these cases, either the community chose not to participate or the enumeration was interrupted before completion, as in the event of natural disasters such as forest fires (Statistics Canada 2013). The Métis data cover people who self-identified as Métis. This could be anyone who thinks he or she may have Indigenous ancestry, rather than those who meet the Métis National Council definition ${ }^{1}$ of who is Métis. This practice may serve to inflate the estimates of how Métis people are doing on these indicators. Métis writer Chelsea Vowel discussed the phenomenon of settlers (non-Indigenous Canadians) claiming Indigenous ancestry, particularly Métis, by virtue of some real or fictitious great-great-grandmother or other relative, in order to appear "edgy" or to legitimize their claims to land (Apihtawikosisan 2015).

The Aboriginal People's Survey (APS) is conducted every five years, usually one year after the Census. It uses the Census/NHS frame (i.e., names, addresses, and contact information) gathered during the Census/NHS to identify households in which Indigenous ("Aboriginal") people are likely to live. The APS is invaluable, but also a problematic source of comparative data for a number of reasons. The first is that it does not include First Nations people who live on-reserve (Bougie et al. 2013). This likely serves to hide the depth

1 "'Métis' means a person who self-identifies as Métis, is distinct from other Aboriginal peoples, is of historic Métis Nation Ancestry and who is accepted by the Métis Nation" (Métis National Council 2014). 
of poverty and educational inequality experienced by the Aboriginal population. The second is that it includes self-identified Métis people, which, as discussed in the context of the NHS, may encompass people who do not meet Métis definitions of who is considered Métis.

For the 2012 APS, 2,457 Inuit out of a total Inuit population in Canada of 59,445 were sampled (Bougie et al. 2013). This gives us a picture of Inuit overall, but in the published materials, they are not broken down by geographic location. The APS questions focus on education, employment and health, and are designed to complement the Census and National Household Survey. The APS data on education and employment were published in a descriptive article by Statistics Canada analysts Evelyne Bougie, Karen Kelly-Scott, and Paula Arriagada (2013). Health data are available in Inuit Health: Selected Findings from the 2012 Aboriginal Peoples Survey, by Statistics Canada analyst Susan Wallace (2014), which also uses data triangulated from the 2012 Canadian Community Health Survey. The sample size of Inuit was 3,668 persons, sufficient to give breakdowns by region.

Sometimes Statistics Canada separates Inuit out as a group, and sometimes it does not. For example, there are no Inuit data in Statistics Canada's publication Aboriginal People and the Labour Market: Estimates from the Labour Force Survey, 2008-2010, in which Inuit are amalgamated with other Indigenous groups. Statistics Canada will separate out the data only if the sample size is large enough. Thus we are unable to get Inuit-specific data from the Labour Force Survey, and must rely on the NHS and APS for Inuit labour force information.

The General Social Survey on Victimization is one of the only GSS cycles to be conducted in the Canadian territories as well as the provinces. Inuit are not reported as a separate group in the GSS. However, we can get a glimpse of Inuit through data collected in Inuit Nunangat (regions where Inuit live), comprising Nunavut, Nunavik (northern Quebec), and Nunatsiavut (Labrador and the Inuvialuit region of the Northwest Territories). This is flawed, because it is based on regions (which also includes data on non-Inuit), rather than who identifies as Inuit. Twenty-seven person of Inuit no longer live in Inuit Nunangat, so they are not captured by this method at all.

For some types of data, figures for Inuit are just not available, and Nunavut data are used as a stand-in for Inuit. However, sixteen percent of Nunavummiut are not Inuit (Nunavut Department of Executive and Intergovernmental Affairs 2015), and slightly more than half (54.5 percent) of Inuit do not live in Nunavut (Statistics Canada 2015).

Statistics Canada enters into data partnerships that allow it to collect national data that might otherwise not be accessible to it. An example of a partner is the Uniform Crime Reporting (UCR) System, which participating police services across the country use to register criminal charges. Other partners include provincial and territorial birth and death registries. Put together, these data form a national picture. These linkages do not tend to yield much in the way of data on Indigenous peoples, as Indigenous status is not always collected at source or may be unreliable. So, for example, to get an estimate of Indigenous stillbirth and infant death rates for Quebec using Statistics Canada's Infant Birth-Death 
Linked File, postal codes for communities where a lot of Indigenous people live were used as a stand-in for Indigenous status. Communities that shared postal codes with nonIndigenous communities could not be used because it would be impossible to tell from the data who was Indigenous and who was not.

The advantage of Statistics Canada surveys is their sample sizes, which exceed those of most non-medical academic studies. A quantitative survey with a large sample size can show how prevalent an issue is, but lacks the personal detail of qualitative studies, which can add texture, depth and understanding to an issue. The only other survey coming close to Statistics Canada in terms of sample size was the 2007-2008 International Polar Year (IPY) Inuit Health Survey, which approached 2,796 Inuit households (only in Inuit regions), of which sixty-eight percent participated, for a total of 1,901 responses (Minich et al. 2011).

\section{Data Access}

The APS is available in a Public Use Microdata File (PUMF). Those who have the training and technology can go to the Statistics Canada website and order the file, and then manipulate it with a statistical software package such as SAS, SPSS, or Stata to get at the data one needs. Many organizations and individuals do not have this capacity. These microdata files are available to colleges and universities under the Data Liberation Initiative. Small community groups or even larger but underfunded organizations that have no link to colleges or universities have difficulty accessing the data.

Statistics Canada has Aboriginal Liaison Officers who offer 500 hours of free data manipulation to selected national Aboriginal organizations. The national organization for Inuit, Inuit Tapiriit Kanatami (ITK), used 2006 APS and 2006 Aboriginal Children's Survey data to produce "Naasautit: Inuit Health Statistics" on its Inuit Quajisarvingat Knowledge Centre website (http://www.inuitknowledge.ca/naasautit). Health is very broadly defined on this interactive site, and includes economy, governance, environment, housing, knowledge and learning, culture and language, and environment as well as access to health services, community and family, food security, health status, and health behaviours. The Naasautit data directory was funded by Health Canada's Aboriginal Health Transition Fund (2007-10) and includes data for Inuit regions as well as for Inuit overall. This is the only site in Canada in which statistics about Inuit are gathered in an easily accessible format. In recent years, national Aboriginal organizations have experienced major cutbacks, borne disproportionately by Inuit (Barrera 2015). It is unknown whether ITK has the time or the resources to update this site with more recent data.

\section{Inuit History, Colonization and Framework for Understanding the Statistics}

Inuit are the most recently colonized of all Indigenous peoples in Canada. Although they have been in contact with Qallunaat (white people) since the whalers of the 1700s and, later, missionaries, traders, and RCMP, it was not until the 1940s to 60s that the government of Canada seized active control of Inuit land and people. Within one generation, nomadic people who had governed themselves fully and lived off the land were subject to several 
Canadian government policies that had an enormous impact on their lives, their ability to make their own decisions, and their view of themselves, as well as their trust of the Canadian government. These policies included the following.

1. Residential schools. The Truth and Reconciliation Commission (TRC) (2015) documented in detail the Canadian government policy of taking Indigenous children, without parental consent if necessary, and sending them to under-resourced, understaffed schools at which they were separated from siblings, taught the language, history and religion of the colonizers, and subject to harsh and unusual punishment for speaking their own language or practicing traditional beliefs. Even those at some later schools at which this type of punishment was no longer used lost their language and culture because they were not taught. Although there were some day schools and hostels in the north, some Inuit children were sent so far away that they were separated from their parents for years at a time (TRC 2015). The TRC noted that the impact on Inuit was particularly devastating for a number of reasons: the schools in the north were among the last to close, so there is a disproportionate number of Inuit survivors still living; the standard of education received was even lower than that of other residential schools; and some northern schools were particularly infamous for decades of sexual abuse and cruelty.

2. Settlement, relocation, and broken promises. The government of Canada began to relocate Inuit as early as 1920, at first in order both to facilitate hunting and assert Arctic sovereignty (Bonesteel 2006), but from the 1940s onward, the government tried to disengage Inuit from their traditional nomadic life and move them into permanent settlements, which led to widespread dependence on government assistance (ITK 2015). In 2010, the government of Canada apologized for the hardships experienced by families from Inukjuak and Pond Inlet who were relocated to the harsher conditions of the high Arctic to found the settlements of Grise Fiord and Resolute Bay during the 1950s (Duncan 2010). The government also apologized for having broken its promises regarding the conditions that Inuit would face, the supplies they would receive, and their ability to return to their original homes if they did not like the new settlement areas (Duncan 2010).

3. Disruption caused by distant medical treatment. By the 1960s, about a third of Inuit were infected with tuberculosis (TB), a disease that came with Qallunaat. A medical ship came to Inuit coastal communities to diagnose people and take them to southern Canada for treatment, whether they wanted to go or not (Grygier 1997). The Canadian government decided on mass evacuation of Inuit as a policy instead of building hospitals in the north or expanding existing facilities (Grygier 1997; Olofsson et al. 2008). The treatment usually lasted years, and many never returned to their homes (Grygier 1997). Families lost touch with their children and did not know where they were. Olofsson et al. (2008) described the experience as one of "fear and desperation" because of the forced separation from family that it involved, and the lack of knowledge on the part of those left behind about where people were being taken or whether they 
would ever return. Many Inuit families today are still looking for where relatives who died during hospital stays may be buried, as they were never informed (Qikiqtani Truth Commission 2009). As well, because of the lack of consistent availability of doctors in the Arctic, a practice developed of sending Inuit women away to give birth in southern cities where they knew no one and no one spoke their language, which disrupted the traditional lifelong relationship between Inuit midwives and the children they delivered (Pauktuutit 2015).

4. Sled dog slaughter. In the 1950s and 60s, the Royal Canadian Mounted Police (RCMP) shot any Inuit sled dogs that they thought were sick, were at risk of being sick, or were perceived by the RCMP to be dangerous. This led to a massive cull of sled dogs, which were the primary means of transportation and hunting for Inuit at the time. This had a profound effect on Inuit daily life and the self-perception of Inuit men as hunters and providers (Inuit Tuttarvingat 2009).

5. Eskimo numbers. Beginning in the 1940s, the government of Canada decided to count the Inuit population. Royal Canadian Mounted Police (RCMP) officials found it difficult to pronounce and spell Inuit names, and traders, government officials, and medical personnel also pressed for some means of identifying Inuit apart from using their names, for which the spelling was not standardized (Bonesteel 2006). Each Inuk was registered and given a metal disc to wear at all times with an E-number (Eskimo number) engraved on it. So, for example, if an Inuk went to the hospital, he or she would have on his or her chart a first name and E-number, or just an E-number, whereas all the other patients would be known by their full names. Today, some Inuit are having their own or their parents' E-numbers tattooed onto their skin. JUNO Award nominee Lucie Idlout's song "E5-770, My Mother's Name" is a testament to the continuing bitterness about this government practice. It was not until the 1970s that Inuit were allowed to choose and register their own official names (Bonesteel 2006).

What can we learn of benefit to data collection and analysis from this context and this history of profound disempowerment engendered by Canadian government attempts to count and "help" Inuit? I suggest asking the following questions:

1. What data are collected? Is the government collecting data it thinks are important? What do Inuit think, and what are their data needs?

2. How are the data collected? Is it respectful, and developed with the participation of Inuit? Does it take the context of Inuit daily life into account?

3. How are the data described and interpreted to the public? Do the resulting reports represent Inuit perspectives on their own situation? Are they useful to Inuit as well as others? Do they take into account the context of how and why Inuit fare so poorly on many socioeconomic indicators? Do they take the range and diversity of Inuit into account? Do they leave the reader/user with a sense of despair about Inuit, or do they indicate how Inuit are responding to the challenges these indicators pose?

The next sections address issues of data collection and reporting. 


\section{Data Collection Instruments and Methods}

Statistics Canada consults with a broad range of stakeholders when revising the Census and major surveys to ensure that they continue to be relevant. It also performs qualitative testing of new or revised questions to ensure they are understood. As a result of consultation, "Inuit (Eskimo)" on the 2006 Census was replaced by "Inuk (Inuit)" on the 2011 NHS (Statistics Canada 2011a). Statistics Canada consulted with some Indigenous organizations in the development of the APS, and the Indigenous footprint can be seen in data on cultural/ traditional activities and language. The APS represents a minority of the data collected by Statistics Canada. Inuit are normally represented by the national organization Inuit Tapiriit Kanatami in consultations, but there may be a lack of capacity for either the organization or Statistics Canada to consult more widely and regularly with Inuit about data needs and interests.

When Statistics Canada collects data as an agency of government, its agents may receive general training that may not necessarily extend to an awareness of the history of how the government of Canada counted Inuit, the history of Canadian government intervention with Inuit, or the impact of these actions, which are ongoing. Not everyone trusts the government of Canada, given this recent legacy. People who do not want to cooperate with the Census or other surveys are not counted, so Statistics Canada does not get a full count of Inuit in Canada. This is true also of other groups that may resist the Census. Statistics Canada numbers, not numbers collected by Inuit agencies, are often used for official purposes, such as the allocation of resources by the federal government and other levels of government, so an accurate count is important.

Statistics Canada makes efforts in northern Canada to work through organizations and media to ensure people are enumerated. It is not unusual to see Inuit organizations and northern media encourage people to participate. The Census/NHS is conducted in person by a Statistics Canada enumerator (Statistics Canada 2011b), which bypasses the problem of low literacy skills and introduces an element of personal contact, yielding response rates that are comparable to those in southern Canada. Now that 27 percent of Inuit live outside traditional Inuit lands (Statistics Canada 2015), it is unclear whether these efforts to ensure Inuit participation reach them in urban areas. There is no particular outreach for urban Inuit. We know from urban Inuit organizations that homelessness among Inuit is high (Gregoire 2015). Statistics Canada has not yet developed a reliable way of including transient and homeless populations in the Census or major surveys.

\section{Data Interpretation and Reporting}

Statistics Canada has a legislated mandate to collect information from Canadians, and it seeks to be relevant. It does not need to conform to the Tri-Council Policy Statement: Ethical Conduct for Research Involving Humans (CIHR et al. 2014), which governs research in Canada. Chapter 9 of the statement deals with research with Aboriginal peoples, and specifies that consultation needs to take place with communities, must involve the research 
participants, and, importantly, should give back to communities and participants in a form the research participants want and think is relevant.

Statistics Canada reports are interesting and informative, but sometimes present information in a way that cannot be used for general purposes. For example, in The Education and Employment Experiences of First Nations People Living Off Reserve, Inuit, and Métis: Selected Findings from the 2012 Aboriginal Peoples Survey, there is not a single indication of Inuit income because it is separated in terms of high school leavers and high school completers. However, ITK's profiles of Inuit (https://www.itk.ca/publication/inuitstatistical-profile), which are based on the 2006 APS data, contain a figure for average income of all Inuit. The issue of the income of high school leavers and completers is an important one, but the document was the only one published that contained any income information for Inuit from the 2012 data. Statistics Canada has in recent years tried to build a better relationship with national Aboriginal organizations, but perhaps even further partnerships could help them choose which data presented in what manner might be most accessible and useful for smaller Indigenous community organizations and individuals.

Income data for Inuit can be misleading because of how household income is typically reported. This is an example in which Statistics Canada did put the Inuit data in context (Wallace 2014):

According to the 2011 National Household Survey, the median household income for Inuit in 2010 was $\$ 74,021$ while the median household income for the total population of Canada $\$ 74,777$. In Inuit Nunangat, the household income was $\$ 77,935$; outside Inuit Nunangat it was $\$ 64,215 \ldots$. While the median household income for Inuit inside Inuit Nunangat is higher than the median household income for Inuit outside of Inuit Nunangat, as well as for the total population of Canada, the cost of living in the north is substantially higher than that of southern Canada (Aboriginal Affairs and Northern Development Canada, 2014; Rogan, 2003). In addition, according to the NHS, households in Inuit Nunangat are larger than outside Inuit Nunangat. The median household size in Inuit Nunangat is 5 people while for the total population of Canada, the median household size is 3 people. In essence, while the median household income in Inuit Nunangat is higher than the median household income of the total population of Canada, there is actually less income per person than outside Inuit Nunangat.

However, sometimes the way statisticians phrase findings about life-and-death health issues can be perceived as insensitive. For example, a Statistics Canada study (Gilbert et al. 2015) about stillbirths in Northern Québec reported:

Stillbirth rates for Aboriginal people living on First Nations reserves, in Cree and Naskapi communities and in Inuit communities, were significantly higher than for non-Aboriginal people, but differences were not statistically significant after adjustment for maternal characteristics, multiple birth and geographic isolation.... Infant mortality was higher for all Aboriginal groups. However, on First Nations reserves, the difference disappeared after adjustment for maternal characteristics, multiple birth and geographic isolation. 
Being Indigenous in Canada in the early $21^{\text {st }}$ century is associated with earlier and more frequent births, less education, lower incomes, and less access to health care. What the data reveal, however, is that there is nothing inherent in being Indigenous that leads to stillbirths; it is the conditions that a disproportionate number of Indigenous people experience that are leading to these tragedies. It is painful to lose a baby, and Indigenous peoples are at greater risk of losing their babies, of experiencing unnecessary deaths in their families, as a result of their living conditions. That is the unstated implication of the phrases "not statistically significant" and "the difference disappeared." Given that not all users of a report on Indigenous stillbirths will be statisticians (some may be medical professionals, community workers, Indigenous organizations, or families who have experienced the situation discussed in the report), it would be wise to deal with the issue sensitively and make implications clear.

Sometimes data reports can be perceived as insensitive if they lack sufficient explanatory context, as this can contribute to the stereotyping of groups. Inuit Tapiriit Kanatami former President Terry Audla (2012) stated, "There's a long, graphic, and unhappy list of economic and social development indicators revealing the pronounced and enduring gaps in basic well-being between Inuit and other aboriginal peoples on the one hand and the general Canadian population on the other." It is important to keep in mind when reading, for instance, that Inuit have the highest suicide rate and the lowest high school graduation rate in Canada, even among Indigenous groups, that the context is that of recent, rapid full-scale colonization. If a person's home and land are taken over without permission by people of a different race and language; if he or she is given no choice but to live where the strangers say; and if he or she has children taken away to schools or hospitals and has the only means of transport and food-gathering depleted, it should be no surprise that marginality, culture shock, and social dislocation will ensue.

Contextual information should also take into account the present as well as the past, in order to avoid feeding prevalent stereotypes. Stereotypes about Indigenous peoples have affected the medical care they receive in Canada (Allan and Smylie 2015), and both teachers' behaviour toward and expectations of Indigenous students (Riley and Ungerleider 2012). Inuit are very active in dealing with the problems caused by colonization. In the 1970s, Inuit founded organizations to represent their interests, and since then they have negotiated five land claims, created a new Canadian territory, and established services and supports to help other Inuit with challenges such as depression, alcohol abuse, drug abuse, family violence, and suicide. One of the key concepts that appears in Inuit organizational literature is that Inuit are resilient (Morris and Crooks 2015).

Context helps users understand the data - why the data say what they do and how they may develop in future. An example of placing "bad news" in context is McInturff's (2015) statistical report on the gender gap on economic security, leadership, health, personal security, and education in Canada's 25 largest metropolitan areas. For each area, she also highlights some initiative being taken to address the challenge of reducing the gap, usually the work of a local women's organization. Without the historical context and without any 
indication that Inuit are in fact establishing services and initiatives on their own behalf, some people, faced only with the statistics stripped of context, may believe that there is something wrong with Inuit, or that they are helpless. This is not the case, and steps could be taken to ensure that statistical reports produced by the government of Canada do not inadvertently leave that impression.

Statistics Canada does include some context when it can, but its capacity to produce analytical reports has been cut back in recent years. Nevertheless, it is crucial to include a context for Indigenous statistics as part of the government's stated efforts to undertake a "renewal of the relationship between Canada and Indigenous peoples" (Trudeau 2015) and promote reconciliation and understanding.

\section{Conclusion}

The Truth and Reconciliation Commission (2015) underlined the importance of knowing the history and context of Indigenous peoples in Canada, and how today's institutions continue to be shaped by this legacy to detrimental effect. In developing and revising data-gathering instruments, in the process of gathering data, and in describing data, statisticians and datacollection agencies can become more familiar with this context and the implications of this history. In addition, the context of the data also facilitates understanding and may help avoid the impression that all is hopeless.

Statistics Canada’s efforts to build relationships with Inuit organizations and communities are laudable and should be prioritized. Statistics Canada has laid a significant foundation in consultation, which could be expanded. In particular, a review of the definitions of the term "Métis" and the development of methods to cover reserves and institutions fully might better capture the numbers and situations of Indigenous peoples in Canada. The development of outreach strategies and methodologies to include transient and homeless persons would not only benefit Inuit, but all Canadians.

Governments, researchers, social service agencies, and Inuit all benefit from accurate counts of Inuit, including those in urban areas, presented with sufficient context to allow for clear understanding of the data. 


\section{Bibliography}

Allan, B., and J. Smylie. 2015. First Peoples, Second Class Treatment. Toronto: Wellesley Institute.

Apihtawikosisan. 2015. "Settlers Claiming Métis Heritage Because They Just Feel More Indigenous." Rabble.ca. Accessed March 12. http://rabble.ca/blogs/bloggers/ apihtawikosisan/2015/03/settlers-claiming-m\%C3\%A9tis-heritage-because-theyjust-feel-more-.

Audla, T. 2012. "Mr. Terry Audla (President, Inuit Tapiriit Kanatami) at the Finance Committee." openparliament.ca, October 29th. Accessed January 17, 2015. openparliament.ca/committees/finance/41-1/84/terry-audla-1/only/.

Barrera, J. 2015. "Aboriginal Organizations Hit with $\$ 60$ million Worth of Cuts, Inuit Faced Steepest Reduction: AFN Analysis." Aboriginal Peoples Television Network (APTN) National News, January 13. Accessed February 10, 2015. http://aptn.ca/ news/2015/01/13/aboriginal-organizations-hit-60-million-worth-cuts-inuitfaced-steepest-reduction-afn-analysis/.

Bonesteel, S. 2006. Canada's Relationship with Inuit: A History of Policy and Program Development. Ottawa: Department of Indian Affairs and Northern Development Canada.

Bougie, E., K. Kelly-Scott, and P. Arriagada.2013. The Education and Employment Experiences of First Nations People Living Off Reserve, Inuit, and Métis: Selected Findings from the 2012 Aboriginal Peoples Survey. Ottawa: Statistics Canada. Accessed January 15, 2015. http://www.statcan.gc.ca/pub/89-653-x/89-653-x2013001-eng.htm.

Canadian Institutes of Health Research (CIHR), Natural Sciences and Engineering Research Council of Canada (NSERC), and Social Sciences and Humanities Research Council (SSHRC). 2014. Tri-Council Policy Statement: Ethical Conduct for Research Involving Humans. 2nd ed. Ottawa: CIHR, NSERC, SSHRC.

Duncan, J. 2010. Apology for the Inuit High Arctic Relocation. Ottawa: Department of Indian Affairs and Northern Development Canada. Accessed January 2, 2016. https://www.aadnc-aandc.gc.ca/eng/1100100016115/1100100016116.

Gilbert, N.L., N. Auger, and M. Tjepkema. 2015. Stillbirth and Infant Mortality in Aboriginal Communities in Quebec. Ottawa: Statistics Canada. Accessed March 24, 2015. http://www.statcan.gc.ca/pub/82-003-x/2015002/article/14139-eng.htm. 
Gregoire, L. 2015. "Ottawa Org Building National Urban Inuit Strategy." Nunatsiaq News. October 13. Accessed January 1, 2015. http://www.nunatsiaqonline.ca/stories/ article/65674ottawa_org_building_national_urban_inuit_strategy/.

Grygier, P.S. 1997. A Long Way from Home: The Tuberculosis Epidemic among the Inuit. Montreal and Kingston, Canada: McGill-Queen's University Press.

Inuit Tapiriit Kanatami (ITK). 2015. “Inuit and Europeans.” Accessed July 15, 2015. https:// www.itk.ca/about-inuit/inuit-and-europeans.

McInturff, K. 2015. The Best and Worst Places to Be a Woman in Canada 2015:

The Gender Gap in Canada's 25 Biggest Cities. Ottawa: Canadian Centre for Policy Alternatives.

Métis National Council. 2014. “Citizenship." Accessed December 14, 2014. http://www. metisnation.ca/index.php/who-are-the-metis/citizenship.

Minich, K, H. Saudny, C. Lennie, M. Wood, Williamson-Bathory, Z. Cao, and G.M. Egeland. 2011. "Inuit Housing and Homelessness: Results from the International Polar Year Inuit Health Survey 2007-2008." International Journal of Circumpolar Health 70 (5): 520-31. doi:10.3402/ijch.v70i5.17858.

Morris, M., and C. Crooks. 2015. "Structural and Cultural Factors in Suicide Prevention: The Contrast between Mainstream and Inuit Approaches to Understanding and Preventing Suicide." Journal of Social Work Practice 2015(July 3): 1-18. doi: 10.1080/02650533.2015.1050655.

Nunavut Department of Executive and Intergovernmental Affairs. 2015. "Nunavut FAQs." Iqaluit, NU: Government of Nunavut. Accessed December 24, 2015. http://www. gov.nu.ca/eia/information/nunavut-faqs.

Olofsson, E., T.L. Holton, and I. J. Partridge. 2008. "Negotiating Identities: Inuit Tuberculosis Evacuees in the 1940s-1950s." Études/Inuit/Studies 32(2): 127-49. doi:10.7202/038219ar.

Pauktuutit Inuit Women of Canada. 2015. "Inuit Midwifery”" Accessed July 31, 2015. http:// pauktuutit.ca/health/maternal-health/midwifery/.

Qikiqtani Truth Commission. 2009. QTC Background Reports: Updates \& Executive Summaries. Iqaluit, Nunavut: Qikiqtani Inuit Association. 
Riley T., and C. Ungerleider. 2012. "Self-Fulfilling Prophecy: How Teachers' Attributions, Expectations, and Stereotypes Influence the Learning Opportunities Afforded Aboriginal Students." Canadian Journal of Education 35(2): 303-33.

Statistics Canada. 2015. Population and Demographic Distribution. Aboriginal Statistics at a Glance. 2nd ed. Ottawa: Statistics Canada. Accessed December 24, 2015. http:// www.statcan.gc.ca/pub/89-645-x/2015001/pop-concept-eng.htm.

Statistics Canada. 2013. Aboriginal Peoples in Canada: First Nations People, Métis and Inuit. Catalogue no. 99-011-X2011001. Ottawa: Statistics Canada.

Statistics Canada. 2011a. Aboriginal Peoples Technical Report, National Household Survey. Ottawa: Statistics Canada. Accessed March 24, 2015. http://www12.statcan.gc.ca/ nhs-enm/2011/ref/reports-rapports/ap-pa/index-eng.cfm.

Statistics Canada. 2011b. National Household Survey User Guide. Ottawa: Statistics Canada.

Statistics Canada. 2010a. Aboriginal Statistics at a Glance. Ottawa: Statistics Canada.

Statistics Canada. 2004. Overview - The Inuit population in Canada: A profile of Canada's Inuit Population. Ottawa: Minister of Industry.

Trudeau, J. 2015. Statement by Prime Minister on Release of the Final Report of the Truth and Reconciliation Commission. Ottawa: Office of the Prime Minister of Canada.

Truth and Reconciliation Commission. 2015. Canada's Residential Schools: The Inuit and Northern Experience. The Final Report of the Truth and Reconciliation Commission of Canada, Volume 2. Montreal and Kingston: McGill-Queen's University Press.

Usalcas, J. 2011. Aboriginal People and the Labour Market: Estimates from the Labour Force Survey, 2008-2010. Statistics Canada Catalogue no. 71-588-X-No. 3. Ottawa.

Wallace, S. 2014. Inuit Health: Selected Findings from the 2012 Aboriginal Peoples Survey. Ottawa: Statistics Canada. Accessed March 3, 2015. http://www.statcan.gc.ca/ pub/89-653-x/89-653-x2014003-eng.htm. 